\title{
Effect of COVID-19 on Psychological Status among Nurses Working at Isolation Hospital
}

\section{Asmaa Salah Ibrahim ${ }^{1}$, Omayma Abo- Bakr Osman² and Faten Mohamed Ahmed ${ }^{3}$}

(1) B.Sc. Nursing, 2009, Faculty of Nursing, Ain Shams University, Egypt, (2) Professor of Psychiatric and Mental Health Nursing, Faculty of Nursing, Ain Shams University, Egypt and (3) Assistant Professor of Psychiatric and Mental Health Nursing, Faculty of Nursing, Benha University, Egypt

\section{Abstract}

Background: COVID-19 affects on nurses psychological attitudes. Nurses often face, unfamiliar environment in the isolation unites, and workload, long hours, these may increase the level of anxiety, depression and stress among nurses. Aim of study: Was to assess the effect of covid-19 on psychological status among nurses working in isolation hospital. Research design: A descriptive design was utilized. Sample: A convenience sample of 169 nurses included in the study. Setting: The study was conducted at Qaha isolation hospital in Qalyubiyah Governorate Tools of data collection: Two tools were used. I: An interviewing questionnaire to assess nursing staff socio demographic data, occupationalfactors and experience acquired to nurses from caring of covid-19 patients. II: Depression, Anxiety and Stress Scale (DASS- 21). Results: Slightly less than half of the studied nurses had moderate level of depression while slightly more than one third of them had severe anxiety feeling and slightly less than half of the studied nurses had moderate feeling of stress. There was highly statistically significant between total level of depression and total level of stress among studied nurses. In addition, that there is positive correlation between total score of depression, anxiety and total score of stress among studied subjects. Conclusion: The overall psychological status of studied nurses was generally poor during COVID-19 outbreak, and several impact factors associated with nurses' psychological health were identified. Recommendations: Paying attention to nurses' psychological health status while fulfilling their responsibilities especially during sudden disaster as COVID-19.

Keywords: COVID-19, Psychological status, Isolation.

\section{Introduction}

Coronavirus disease 2019 (COVID-

19) is an infectious diseases caused by severe acute respiratory syndrome coronavirus (SARS-COV-2). The disease began at December, 2019 in Wuhan, which capital city of China, and continues to spread rapidly around the world and caused the 2019 coronavirus pandemic. The World Health Organization (WHO) declared a global COVID-19 pandemic on March 11, 2020 and to date has been unable to predict the duration of the pandemic (Lippi et al., 2020).
Nurses plays a pivotal role in healthcare setup in prevention, infection control, isolation, continuous monitoring of the patient. There are occupational risks to providing care during COVID- 19 pandemic and it's also reported that the changes of occupational exposure are relatively higher in nurses. The pandemic not only affects physical health but also mental health and well-being. Mental health and psychosocial consequences of the covid-19 pandemic may be particularly serious for health professionals because of a higher level of exposure. A poorly known contagious disease outbreak, like covid-19, leads to unavoidable stress, 
fear, and anxiety that can be profound among the higher-risk groups, such as healthcare professionals including nurses (Mo et al., 2020).

The psychological health status of nurse was influenced by many factors. Previous studies reported that personal factors such as gender, age, educational level, marital status, having children or not, and personality might be correlated with the mental health among nurses. Additional, external factors including workload, work stress, work environment and training also played important role in influencing the mental health of nurse (Maharaj et al., 2018).

In additional to psychological distress including depression and anxiety has been reported in the health staff working at the isolation hospital of fighting COVID-19. Among health staff, nurses are the most involved in fighting against the COVID-19. Actually, they regularly are in direct contact with patients from the time of admission to the discharge. Therefore, nurses are highly exposed to psychological distress compared to other health workers during the pandemic. Nurses providing intensive and ongoing health services during previous epidemics had been reported to experience the highest level of job stress and mental distress compared to other treatment staff (Eghbali et al., 2020).

The literature has established the ill effects of stress on the nurses' psychological well-being and work outcomes. Stress is generally sourced from situations that a person has no control over, such as a pandemic. There are a lot of studies on how the COVID-19 pandemic has caused much stress to the various healthcare systems across the globe. It has compromised the workforce, particularly nurses. In fact, among the healthcare workers, nurses are found to be the most anxious and stressed in caring for and treating patients infected with the COVID-19 virus (Mo et al., 2020).

Disease outbreaks such as the COVID19 pandemic are anxiety-provoking situations. Anxiety is common among healthcare workers who are directly involved in managing affected patients during pandemics. Further, due to their direct contact with COVID-19 patients, healthcare workers (HCWs) are more exposed to traumatic events such as patients' suffering and death which could further amplify their fears and anxiety (Pappa et al., 2020).

\section{Significance of the Study}

Globally, as of the evening of 17 August 2021, there have been 207, 784, 507 confirmed cases of COVID-19, including 4,370,424 confirmed deaths. In Egypt, The first confirmed case of COVID19 was reported on 14 February 2020. For A Chinese young man coming from Wuhan, China. The data are updated daily, from 3 January 2020, 17 August 2021; there have been 285, 465 confirmed cases ofCOVID-19 with 16,625 confirmed deaths (WHO, 2021).

\section{Aim of the study}

This study aimed to assess the effect of COVID-19 on psychological status among nurses working at isolation hospital.

\section{Research question}

What is the effect of COVID-19 on psychological status among nurses working at isolation hospital?

\section{Subject and Methods \\ Research Design:}

A descriptive design was utilized in this study to achieve the aim of the study.

\section{Research setting:}

The study was conducted in Qaha isolation hospital in Qalyubiyah Governorate affiliated 
to the ministry of health. This hospital was designed to covid-19 referral hospital by the ministry of health to deliver services and care to confirmed covid-19 patient.

\section{Sample:}

A convenience sample of 169 nurses was eligible to participate in this study, was included in the study according to the following equation: (Kerjcie \& Morgan, (1970).

$\mathrm{S}=\mathrm{X} 2 \mathrm{NP}(1-\mathrm{P}) \div \mathrm{d} 2(\mathrm{~N}-\mathrm{P})+\mathrm{X} 2 \mathrm{P}(1-\mathrm{P})$

Ten percent of those nurses were selected for pilot study and were excluded from the sample. There for the remaining nurses constituted the main sample after apply inclusion and exclusion criteria.

\section{Inclusion criteria:}

-Both sexes (male and female)

-All nurses who work in isolation hospital.

\section{Tools of data collection:}

Two tools were utilized for data collection

Tool one: An interviewing questionnaire containing three parts:

Part 1: Socio-demographic characteristic of the nurses that included 8 items.

Part 2: Questionnaire related to nurses' occupational factors

It was by developed by researcher based on the literature review. This part included 4 items.

Part 3: Experience acquired to nurses from caring of covid-19 patients

It was prepared by the researcher based on literature review. This part includes 19 items to assess nurse's experience gained from caring of covid-19 patients. This part included nurse's knowledge about covid-19 (4 items), physical effect (6 items), support resources (5 items), nursing relationship with others (4 items).

\section{Scoring system}

For nurses knowledge about covid-19, was given (1) for yes (correct answer) and (0) for no (incorrect answer). Nurses' knowledge was considered "satisfactory" if the score ranged between (3-4) $70 \%$ or more, was considered "unsatisfactory" if the score ranged between (0-2) Less than $70 \%$. For physical effect of covid-19 on nurses status was given (1) for yes and (0) for no statement. Was considered "high effect" if the score ranged from (4-6) $70 \%$ or more, and was considered "low effect" if the score ranged between (0-3) Less than $70 \%$. For supportive resources to nurses was given (1) for yes and (0) for no statement. Was considered "adequate support" if the score ranged from (4-5) $70 \%$ or more, and was considered "inadequate support" if the score ranged between (0-3) Less than $70 \%$. For pattern of relationship of nurses with others was given (1) for yes and (0) for no statement. Was considered "positive relation "if the score ranged between (3-4) $70 \%$ or more, and was considered "negative relation" if the score ranged between (0-2) less than $70 \%$.

\section{The total scoring system (19 items):}

Was considered "positive experience" if the score ranged from (13-19) 70\% or more, and was considered "negative experience" if the score ranged between (0-12) less than $70 \%$. This scoring system was developed by the researcher with help from the statistical specialist.

Tool two: Depression, Anxiety and Stress Scale (DASS- 21).

It is a sort form of self- report scales developed by (Lovibond \& Lovibond 1995) to assess psychological change on three subscales (depression, anxiety and stress). This scale included 21 items (7 items to evaluate depression, 7 items of them to evaluate 
anxiety and 7 others to evaluate stress). Each item demonstrated a feeling in the participant.

\section{Scoring system of DASS scale:}

The answer was classified as the follows:

$1=$ Didn't apply to me at all.

$2=$ Applied to me some degree.

$3=$ Applied to me very much or most of the time.

\section{Total score:}

1- Depression: mild 1-9 $(\leq 42.8 \%)$, moderate $10-15$ (>42.8\%-71.4\%), severs 16-21 (>71.4\%).

2- Anxiety: mild 1-7 ( $\leq 33.3 \%)$, moderate 8-14 (>33.3\%-66.6\%), severs 15-21 (>66.6\%).

3- Stress: mild 1-14 $(\leq 66.6 \%)$, moderate $15-18 \quad(>66.6 \%-85.7 \%), \quad$ severs $19-21$ $(>85.7 \%)$.

\section{Validity of tools:}

To achieve the criteria of trustworthiness of the data collection tools in this study, tools were tested and evaluated for content validity. Arabic translation was done by the researcher for tools of the study and tested for their translation .Content validity was tested by three experts in Psychiatric Mental Health Nursing in Faculty of Nursing at Benha University. According to their opinions modifications were done and the final form was developed. The modification were (modify some words to give the right meaning of the phrase).

\section{Reliability of tools:}

To achieve the criteria of trust and worthiness of the tools of data collection in this study a doctor in statistics checked faces and content of tools. The reliability of the tool (Nurses' experience acquired from working in isolation hospital) was assessed using Cronbach's Alpha reliability. The Alpha Cronbach coefficient after computation was found to be $r$ $=0.969$ while the reliability of the tool
(Depression, anxiety and stress scales (DASS21) was found to be $r=0.91$. Some modifications were done.

\section{Ethical consideration:}

The ethical research considerations, in this study, included the following:

- An oral consent was obtained from nurses to assure voluntary participation for every selected parent who was involved in the sample. Also the purpose of the study was explained to the parents.

- The participants were assured about confidentiality and the privacy of their obtained information throughout the study.

- Participants were informed that they were allowed to choose to participate or not in the study and that they have the right to withdraw from the study at any time during data collection. Subjects were informed that the content of the tools was used for research purposes only.

- Each participant was individually evaluated.

\section{Pilot study:}

A Pilot study was conducted on (10\%) of the total sample to ensure feasibility, objectivity, and reliability of the study tools, and the time needed to complete them, and to identify the problems and obstacles that may be encountered during the study. Modification was done according to the results of this pilot study. Then the finial format was developing under the guidance of the supervisor. This sample was excluded from the actual study sample.

\section{Field work:}

The official permissions were obtained from the director of isolation hospital at Qaha city affiliated AT Kalubyia Governorate. Next the researcher started the process of data collection. Nurse staffs fulfilling the inclusion criteria were 
approached by the Researcher to fill in the Questionnaire according to the following steps:-

- The researcher started the process of data collection by introducing herself to the participants.

- An oral informed consent was obtained from each participant.

- A brief description of the purpose of the study and the type of questionnaire required to fill was given each nurse.

- Then the nurses were handed two out of three questionnaires to fill after receiving the information and instruction required from the researcher of filling the questionnaire.

- Data collect were done through interviewing with the nurses individually in nursing room to maintain social distancing. The researcher started to collect data from nurses 3 day a week from 9Am to $2 \mathrm{Pm}$. Each interview lasted for 15-20 minutes questionnaire methods.

- This process took 12 weeks from the beginning of January 2021 and was completed by the end of March 2021. This process done after the end of the first wave of covid-19 to give the researcher an opportunity to conduct interview.

- The interview was done individually in the nursing room with taking into account the application of social distancing and the obligation to wear personal protective equipment.

\section{Statistical analysis:}

Recorded data were analyzed using the statistical package for social sciences, version 20.0 (SPSS Inc., Chicago, Illinois, USA). Quantitative data were expressed as mean \pm standard deviation (SD). Qualitative data were expressed as frequency and percentage. Statistical significance was considered at:
$\mathrm{P}$-value $<0.05$ was considered significant.

P-value $<0.001$ was considered as highly significant.

P-value $>0.05$ was considered insignificant.

Results:

Table (1): Shows that, the highest percentage of studied subjects were in the age group 25 $<35$ years $(62.7 \%)$. In relation to the studied subjects' sex, $(72.8 \%)$ of the studied subjects were females. Also the table clarified that more than two third were married $(66.8 \%)$. As for the educational level of nurses, $(49.0 \%)$ of studied subjects are graduates of nursing technical institute. Also, the table clarified that more than one quarter of studied subjects didn't take any training courses $(27.2 \%)$, and two thirds of them (66.3\%) need training courses about COVID-19.

Table (2): Shows that nearly half of studied subjects $(45.0 \%)$ had from $5<10$ years of nursing experience. Also, less than half working from 6-12hours per day. Also, nearly two thirds of them $(62.1 \%)$ of them working in intensive care unit. Moreover, this table shows that nearly half of the studied subjects $(49.0 \%)$ have taken one day off per week.

Figure (1): Demonstrate that more than one third of the studied subjects $(35 \%)$ had a mild depression while, slightly less than half were moderate depression $(45 \%)$, also slightly less than one quarter (20\%) had severe depression.

Figure (2): Illustrates that, slightly less than one quarter of the studied nurses $(24.3 \%)$ has mild anxiety, while, more than two fifth of them $(44.2 \%)$ had a moderate level of anxiety also, more than one third of them (31.5\%) had a severe level of anxiety.

Figure (3): Demonstrate slightly more than one quarter of the studied subjects were have mild stress $(27 \%)$ while, slightly less than half were moderate stress $(42 \%)$, also, more than one third were severe stress $(31 \%)$. 
Table (1): Distribution of the studied sample regarding to their socio- demographic characteristics (n=169).

\begin{tabular}{|c|c|c|}
\hline Items & No. & $\%$ \\
\hline \multicolumn{3}{|l|}{ Age (years) } \\
\hline$<25$ years & 37 & 21.0 \\
\hline $25-<35$ years & $\overline{106}$ & $\overline{662.7}$ \\
\hline$\geq 35$ years & 26 & 15.4 \\
\hline \multicolumn{3}{|l|}{ Mean \pm SD $\quad 29.30 \pm 5.57$} \\
\hline \multicolumn{3}{|l|}{ Sex } \\
\hline Female & 123 & 72.8 \\
\hline Male & 46 & 27.2 \\
\hline \multicolumn{3}{|l|}{ Marital status } \\
\hline Single & 49 & 29.0 \\
\hline Married & 1113 & 66.8 \\
\hline Divorced & 3 & 1.0 \\
\hline Widowed & 4 & 2.4 \\
\hline \multicolumn{3}{|l|}{ Level of education } \\
\hline Nurses school & 40 & 23.7 \\
\hline Nurses Technical Institute & 84 & 49.0 \\
\hline Bachelor of Nurses & 35 & 20.7 \\
\hline Postgraduate & 10 & 5.9 \\
\hline \multicolumn{3}{|l|}{ Job } \\
\hline Supervisor & 37 & 21.9 \\
\hline Nurse & 132 & 78.1 \\
\hline \multicolumn{3}{|l|}{ Having children } \\
\hline $\mathrm{No}$ & 55 & 32.5 \\
\hline Yes & 114 & 67.5 \\
\hline \multicolumn{3}{|l|}{ Take any training courses } \\
\hline Yes & 123 & 72.8 \\
\hline No & 46 & 27.2 \\
\hline \multicolumn{3}{|l|}{ Need to training courses about COVID-19 } \\
\hline No & 57 & 33.7 \\
\hline Yes & 112 & 66.3 \\
\hline \multicolumn{3}{|l|}{ If, yes $(\mathrm{N}=112)$} \\
\hline $\begin{array}{l}\text { I do not know how to deal with a Covid-19 patient } \\
\text { in the best way }\end{array}$ & 9 & 8.0 \\
\hline $\begin{array}{l}\text { I lack sufficient experience and information about } \\
\text { Covid-19 }\end{array}$ & 15 & 13.4 \\
\hline $\begin{array}{l}\text { Get to new information on how to deal with disease } \\
\text { and infection control }\end{array}$ & 88 & 78.6 \\
\hline \multicolumn{3}{|l|}{ If, No (N=57) } \\
\hline $\begin{array}{c}\begin{array}{c}\text { I have experiences in dealing with infectious } \\
\text { diseases }\end{array} \\
\end{array}$ & 55 & 96.5 \\
\hline These courses are not important to me & 2 & 3.5 \\
\hline
\end{tabular}


Table (2): Distribution of the studied sample regarding to their occupational factors $(n=169)$.

\begin{tabular}{|c|c|c|}
\hline Items & No. & $\%$ \\
\hline \multicolumn{3}{|l|}{ Years of nursing experience } \\
\hline$<5$ years & 43 & 25.4 \\
\hline $5-<10$ years & 76 & 45.0 \\
\hline$\geq 10$ years & 50 & 29.6 \\
\hline Mean \pm SD & \multicolumn{2}{|c|}{$8.15 \pm 2.36$} \\
\hline \multicolumn{3}{|l|}{ Number of working hours } \\
\hline 6-12 hrs. & 72 & 42.6 \\
\hline$>12-24 \mathrm{hrs}$. & 50 & 29.6 \\
\hline$\geq 24$ hrs. & 47 & 47.9 \\
\hline Mean \pm SD & \multicolumn{2}{|c|}{$17.26 \pm 5.01$} \\
\hline \multicolumn{3}{|l|}{ Current working department } \\
\hline Intensive Care Unit & 105 & 62.1 \\
\hline Inpatient Department & 64 & 47.9 \\
\hline \multicolumn{3}{|l|}{ Number of days off per week } \\
\hline One day a week & 76 & 49.0 \\
\hline Two days a week & 30 & 17.7 \\
\hline More than two days a week & 53 & 37.3 \\
\hline
\end{tabular}

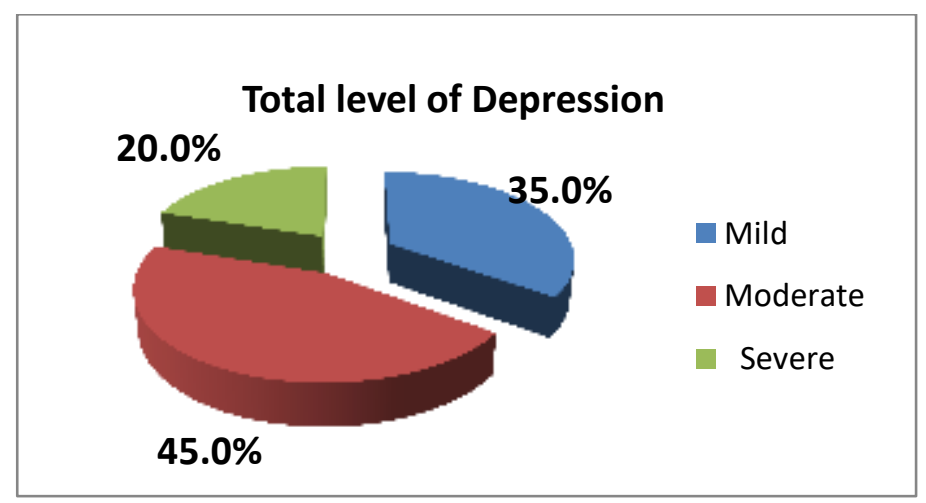

Figure (1): Distribution of the studied subjects according to the total level of depression

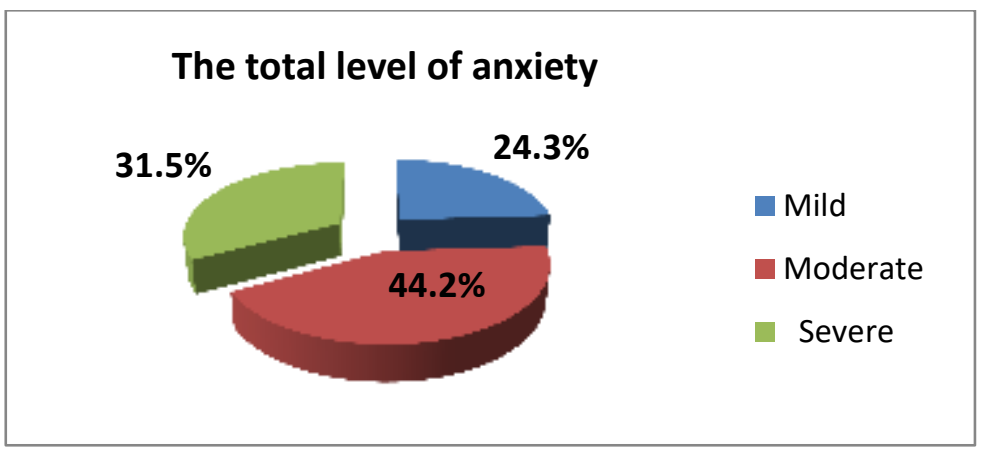

Figure (2): Distribution of the studied subjects according to their total level of anxiety 


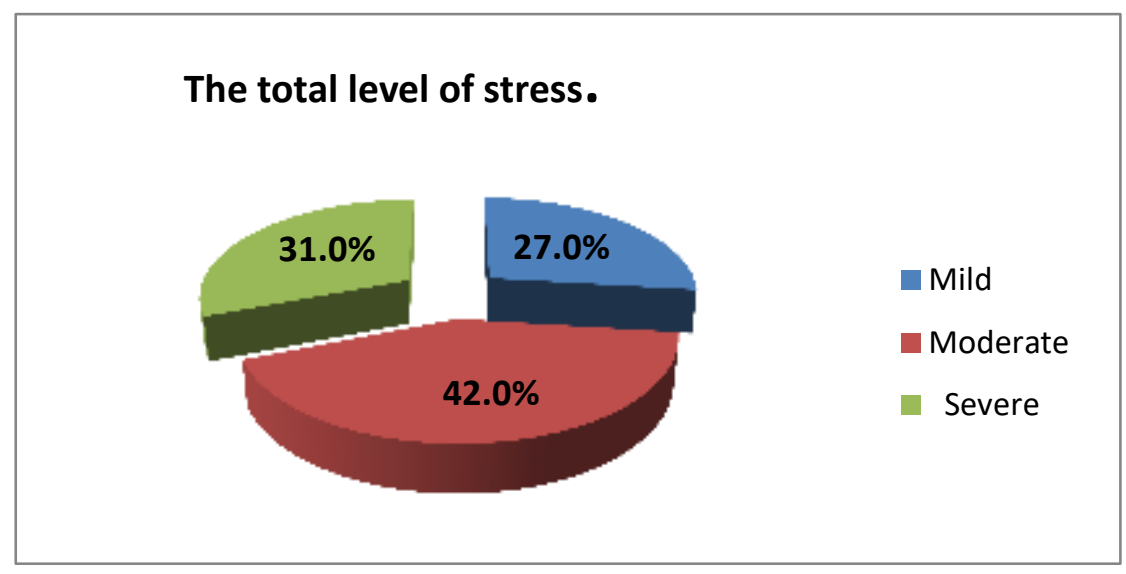

Figure (3): Distribution of the studied subjects according to their total level of stress

\section{Discussion}

The coronavirus pandemic not only affects physical health of nurses but also affects mental health and well-being. Mental health and psychosocial consequences of the COVID-19 pandemic may be particularly serious for health professionals because of a higher level of exposure; also, nurses often face huge psychological pressure as a result of workload, long hours, and working in a highrisk environment (Fiorillo \& Gorwood, 2020). A poorly known contagious disease outbreak, like COVID-19, leads to unavoidable stress, fear, and anxiety that can be profound among the higher-risk groups, such as healthcare professionals (HCPs) including nurses. The mental well-being of HCPs can be negatively affected by fear of being exposed to the COVID-19 cases in hospitals, being separated from families, and confronting the death or illness of patients from COVID-19 (Greenberg et al., 2020).

So, the current study aimed to assess the effect of COVID-19 on psychological status among nurses working at isolation hospital at Al-Qalyubiyah Governorate.
As regard to age, the present study has showed that, nearly two thirds of the studied samples were in age group between 25 and 35 , with the mean age $29.35 \pm 6.070$ years. This might be due to the fact that, this age is the age of working in words and nurses who are older have more administrative work. These findings were agreement with the study done by Mekonen et al., (2020) who assessed the prevalence and associated factors of anxiety, depression, and stress among nurses working in referral hospitals and found that more than half of samples were in the age group range of 25-29 years. In addition, Abdel Aziz et al., (2020) who assessed the predictive factors affecting stress among nurses providing care at COVID-19 isolation hospital" and showed that, the age group of nearly three quarters of their participants was between 20-30 years old.

The results of the present study revealed that, nearly three quarters of the studied nurses were females. The large number of females compared to a minority of males may be due to nursing is female dominated field, so that a lot of males doesn't want to get into it. Also, it is partly because female naturally tend to be drawn to professions that involve 
caring people. This finding was similar to the study done by Labrague \& Los- Santos (2020) who assessed the fear of COVID-19, psychological distress among frontline nurses" and reported that more than two thirds of study participants were female.

Concerning nurses' marital status, the present study revealed that, more than two thirds of studied nurses were married, this might be due to that most of them were in the age of marriage in Egypt and Egyptian culture encouraged for early marriage and the preference to marry an employee with a steady income. These findings were similar to the study done by Mekonen et al., (2020) who found that more than half of their studied samples were married. However, these findings were contradictory to the findings of Abdel Aziz et al., (2020) who revealed that the majority of their samples were single.

As a regard nurses' educational level, the present study showed that, nearly half of studied nurses had a technical nursing institute, from the researcher point of view this might be due to that nurses with technical institute education tend to work as a practitioner nurse, these findings were in agreement with the study conducted by Abdel Aziz et al., (2020) who found that, the majority of studied sample were those of the nursing technical institute. Conversely, the study disagreed with Al Maqbali \&Al Khadhuri, (2021) who studied psychological impact of the COVID-19 pandemic on nurses and concluded that the majority of nurses had bachelor's degree.

As regards to the training courses on infection prevention, the present study revealed that more than one quarter of studied nurses didn't receive infection prevention training course, from the researcher point of view this might be related to the workload on nursing staff during Covid 19 that make no time to conduct or attend any training course. These findings were similar to the study done by Cui et al., (2020) who assessed the Impact of COVID-19 on psychology of nurses working in emergency and fever outpatient and found that more than on quarter of respondents didn't attended any training courses about infection prevention. On the other hand, these results contradicted with Mekonen et al., (2020) who showed that, more than one-third of participants attend and participate in training courses about infection prevention during Covid 19 pandemic.

As regards the need for COVID-19 training course, nearly two third of the studied nurses needed training courses about COVID19 , this might be related to that their need to increase awareness and correct practice to protect themselves and to protect their relatives from transmitted infection and to obtain new information about how to deal with disease and infection control. The previous finding agreed with Jiang et al., (2020) whose study entitled the performance and professionalism of nurses in the fight against the new outbreak of COVID-19 epidemic is laudable and found that nearly half of studied nurses needed training courses regarding COVID 19, methods of transmission and methods of prevention to protect themselves and relatives from infection transmission. Conversely the study disagreed with Al-Dossary et al., (2020) whose study entitled Nurses' demographic information, awareness, attitudes, prevention, and perceptions of COVID-19 during the outbreak in Saudi Arabia" and found that, the majority of nurses had excellent knowledge of COVID-19 and didn't require additional training courses. 
Regarding the occupational characteristics of the studied nurses, the result of the present study illustrated, that nearly half of studied nurses had from $5<10$ years of experience and nearly two thirds of nurses were working in intensive care unit, this might be related to increasing the number of patients who need to be admitted isolation hospitals and needed to intensive care units, where their deteriorating health condition needs more nursing staff to provide a comprehensive care. This finding was consistent with Al-Dossary et al., (2020) who found that more than one third of studied nurses had from $5<10$ years of experience and more than one half of them were working at ICU.

Regarding occupational characteristics of the studied nurses, the findings of the present study indicated that, more than three quarter were providing a place to rest in the hospital, this could be related to the long working hours that nurses spend in isolated areas with COVID-19 patients, so they needed to suitable places of rest, eating, drinking and sleeping. This study agreed with Arons et al, (2020) who reported that health care practitioners who works units with COVID19 patients special break rooms to avoid sharing rest rooms with co-workers.

The results of the present study also illustrated that nearly one fifth of studied nurses mentioned that the hospital didn't provide adequate personal protective equipment, this might be related to that there is a shortage of protective equipment (gowns, gloves, aprons, face shield) due to the excessive use of theses supplies in the pandemic crisis result in spent of protective equipment, the study was in the same line with Mo et al., (2020) whose study entitled "Work stress among Chinese nurses to support Wuhan in fighting against COVID-19 epidemic" and found that nearly one third of study participants illustrated that they had a problem from insufficient equipment and shortage of supplies.

Concerning total level of depression, the current study revealed that slightly less than half of them had a moderate depression. This could due to those the nurses work in close contact with covid-19 patients for longer working hours and the possible fear of dying. This finding of this study were similar to the study conducted by Shaukat et al., (2020) who assess physical and mental health impacts of covid-19 on health care workers and found that the prevalence of depression slightly more than half. Furthermore, the previous results go in the same line with a study done by Ahmad, (2020) who assesses the effect of COVID 19 pandemic on psychological attitudes for nurses' workers at Isolation Hospitals in Baghdad. The study showed that, the majority of nurses feel that the ineffective treatment of the covid19 pandemic increases the incidence of depression; all of nurses feel a depression when they will be a carrier of COVID-19 to their families and friends.

Concerning the distributions of the studied subjects regarding to their level of anxiety; the current study revealed that more than two fifth of them had a moderate level of anxiety while, more than one third of them had a severe level of anxiety this might be due to the greatest fears of health personnel during the pandemic is the possibility of infecting others, specifically family members. As result, those nurses who are worried about infecting family members have a higher risk of developing anxiety. Also the majority of nurses believe that the working at an unfamiliar environment increases anxiety and affects the psychological health. Also, the majority think that a lack of experience in the 
field of infectious diseases leads to increased anxiety and affects the psychological health.

This study congruent with the study done by Aly et al., (2021) who studied "perceived stress, anxiety and depression among healthcare workers facing the covid-19 pandemic in Egypt" and found that, nearly one fifth of nurses had a sever level of anxiety, slightly less than half of the participants had the moderate level of anxiety, while nearly one third of them had mild anxiety. On the same line, Pappa et al., (2020) who assessed "Prevalence of depression, anxiety and insomnia among healthcare workers during the covid -19 pandemic" and found that more than half of studied nurses reports symptoms of anxiety. Conversely, these result disagreed with a study done by Cui et al., (2020) who found that more than half of participants had no anxiety symptoms and more than one quarter of their study participants had a mild anxiety level.

Concerning studied subjects regarding to their total level of stress, nearly one third of studied nurses had a severe level of stress, more than two fifth of them had a moderate level of stress, and slightly more than one quarter of them had mild level of stress. This might be due to stressful and constrained conditions where they are exposed to constant threat of infection and fear from transmission infection for their family. The finding of this study were matched with the study done by Sheraton et al., (2020) who found that, the majority of studied sample had a moderate to severe stress and only the minority of their participants show low perceived stress. However, these results disagreed with the study conducted by Kang et al., (2020) who reported that the majority of participant had mild stress, while more than one fifth of them a had moderate level of stress and the minority of them had a sever level of stress.

Concerning the relation between sociodemographic characteristics and total level of depression, anxiety stress of the studied subjects, the present study revealed that, there was a highly statistically significant relation between each of them and their sociodemographic characteristics, this might be related to that when the age increase or with high educational level and more attendance of training courses, nurses learn new strategies to deal with these psychosocial problems, the result is agreed with Krishnamoorthy et al., (2020) whose study entitled Prevalence of psychological morbidities among general population, healthcare workers and COVID19 patients amidst the COVID-19 pandemic and found that there were a highly statistically significant relation between nurses' demographic characteristics and their level of depression, anxiety and stress.

Conversely, the study was incongruent with the study done by Zhang et al., (2021) who assessed the levels of depression, anxiety, and stress among Hubei pediatric nurses during the COVID-19 pandemic" and found that there was no significant correlation between total level of depression, anxiety, and stress among nurses and their demographic characteristics.

\section{Conclusion}

The Psychological status of studied nurses was generally poor during COVID-19 outbreak. The COVID-19 pandemic effect on psychological status among nurses working at isolation hospital, more than two fifths of the studied nurses had moderate depression, anxiety \& stress. Also, there was highly statistically significant association between total level of depression and total level of stress among studied nurses. 
Moreover, there is positive correlation between total score of depression, anxiety and total score of stress among studied subjects, there was highly statistically significant correlations with at ( $\mathrm{p}$-value $<0.001)$. In addition, the nurses examined considered social support from families and friends to be important during the pandemic, and demonstrated a need for increased social support to adjust to psychological distress.

\section{Recommendations}

\section{In nursing serves:}

- Providing training courses related to COVID-19 protection, personal protective equipment should be always available for all nurses, especially for nurses working in isolation hospital.

- Providing nurses with suitable personal protective equipment is one definite measure that can help to keep the lives of nurses safe and to decrease their fear of becoming infected.

\section{In Education:}

- It is important to pay attention to nurses' psychological health status while fulfilling their responsibilities.

- Provide opportunities for nurses to discuss the stress they are experiencing, support one another, and make suggestions for workplace adaptations during this pandemic.

- Healthcare $\backslash$ managers need to recognize the sources of stress in order to identify potential organizational interventions to maintain nurses' psychological health, safety, and well-being.

- It is importance to providing comprehensive psychological support strategies to reduce the psychological impact of COVID-19 among nurses in an epidemic situation.

\section{In research:}

- Providing psycho-social support programs for nurses may be effective to alleviate negative psychological effects and to enhance mental health of nurses.

- Further study is needed to distinguish of psychological symptoms during and after infectious disease outbreak.

- Further research with a larger sample is recommended.

\section{References}

Abdel Aziz, S. A., Mohamed. A., Karawan, S. G., Abboud, A. H. \& Ahmed AbdelKader, F. (2020). Predictive factors affecting stress among nurses providing care at COVID-19 isolation hospitals at Egypt. Nursing Open. 2021; 8:498-505. https://doi.org/10.1002/ nop2.652

Ahmad, A. (2020). Effect of COVID-19 Pandemic on Psychological Attitudes' for Nurse Workers at Isolation Hospitals in Baghdad City. Indian Journal of Forensic Medicine \& Toxicology, 14(4), pp. 25032507.

Al maqbali, M., \& Al -khadhuri, J. (2021). Psychological impact of the coronavirus 2019 (COVID-19) pandemic on nurses, Japan Academy of Nursing Science, Japan Journal Nursing Science. pp. 1-10

Aly, H., Nemr, N., Kishk, R., \& Elsaid, N. (2021). Stress, anxiety and depression among healthcare workers facing COVID-19 pandemic in. Egypt: a cross-sectional onlinebased study. BMJ Open; 11:

Al-Dossary, R., Alamri, M., Albaqawi, H., Al Hosis, K., Aljeldah, M., Aljohan, M., Aljohani, K., Almadani, N., Alrasheadi, B., Falatah, R., \& Almazan, J. (2020). Awareness, Attitudes, Prevention, and Perceptions of COVID-19 Outbreak among Nurses in Saudi Arabia. International Journal 
of Environmental Research and Public Health, 17, pp. 8269

Arons, M., Hatfield, S., \& Reddy, K. (2020). Pre-symptomatic SARS-CoV-2 Infections and Transmission in a Skilled Nursing Facility. NEJM. DOI: 10.1056/NEJMoa2008457

Cui, S., Jiang, Y., Zhang, L., Kong, D., \& Chu, J. (2020). Impact of COVID-19 on psychology of nurses working in emergency and fever outpatient: A cross-sectional survey. Eur Psychiatry, doi: 10.21203/rs.3.rs20777/v1

Eghbali, M., Negarandeh, R., \& Froutan, R. (2020). COVID-19 epidemic: Hospitallevel response. Nurs Pract Today. 2020; 7(2):81-93

Fiorillo, A., \& Garwood, P. (2020). The consequences of the COVID-19 pandemic on mental health and implications for clinical practice. Eur Psychiatry. 63(1).

Greenberg, N., Docherty, M., Gnanapragasam, S., \& Wessely, S. (2020). Managing mental health challenges faced by healthcare workers during covid-19 pandemic. BMJ.

Jiang, L., Broome, M. \& Ning, C. (2020). The performance and professionalism of nurses in the fight against the new outbreak of COVID-19 epidemic is laudable, International journal of nursing study, Vol.107, No (23), Pp.: 12-18.

Kang, L., Li, Y., \& Hu, S. (2020). The mental health of medical workers in Wuhan, China dealing with the 2019 novel coronavirus. Lancet Psychiatry; 7(3):e14. Doi: 10.1016/S2215-0366(20)30047-X.

Kerjcie, D., \& Morgan, R. (1970). Small sample technique. The NEA Research Bulletin, 38 (December) p.99.
Krishnamoorthy, Y., Nagarajan, R., Saya, K., \& Menon, V. (2020). Prevalence of psychological morbidities among general population, healthcare workers and COVID19 patients amidst the COVID-19 pandemic: A systematic review and meta-analysis, Psychiatry Research, Vol .293 (no.23), Pp.: 35-37.

Labrague, L. J., \& Los Santos, J. A. (2020). Fear of covid-19, psychological distress, work satisfaction and turnover intention among frontline nurses. JNurs Manag.2021 Apr;2 9(3):395-403.doi:10.1111/jonm.13168.

Lovibond, S., \& Lovibond, P. (1995). Manual for the Depression, Anxiety \& Stress Scale. $\quad\left(2^{\text {nd }}\right.$ Ed. $) \quad$ Sydnay: Psychology Foundation; Australian Physiotherapy Association. Published by Elsevier Inc. Volume 56,Issue 3, P.204.

Lippi, G., Sanchis-Gomar, F., Henry, B. M. (2020). Coronavirus disease 2019 (COVID19): the portrait of a perfect storm. Ann Trans Med. 2020; 8(7):497. https://doi. org/10.21037/atm.2020.03.157.

Maharaj, S., Lees, T., \& Lal, S. (2018). Prevalence and risk factors of depression, anxiety, and stress in a cohort of Australian nurses. Int $\mathrm{J}$ Environ Res Public Health; 16(1):Pp.61-70 Doi: 10.3390/ijerph16010061.

Mekonen, E., Shetie, B., \& Muluneh, N. (2020). The Psychological Impact of COVID19 Outbreak on Nurses Working in the Northwest of Amhara Regional State Referral Hospitals, Northwest Ethiopia. Psychology Research and Behavior Management Journal, 13, pp. 1353-1364 https://doi.org/10.2147/PRBM.S291446

Mo, Y., Deng, L., Zhang, L., Lang, Q., Liao, C., Wang, N., \& Huang, H. (2020). Work stress among Chinese nurses to support 
Wuhan in fighting against COVID19 epidemic. Journal of Nursing Management 28(5):Pp.1002-1009.

Pappa, S., Ntella, V., Giannakas, T., Giannakoulis, V. G., Papoutsi, E., \& Katsaounou, P. (2020). Prevalence of depression, anxiety, and insomnia among healthcare workers during the COVID-19 pandemic: A systematic review and metaanalysis. Brain, Behavior, and Immunity, 88, 901-907.

https://doi.org/10.1016/j.bbi.2020.05.026

Shaukat, N., Ali, D. M. \& Razzak, J. (2020). Physical and mental health impacts of COVID-19 on healthcare Workers: a scoping review. Int J Emerg Med13,40(2020). https//doi.org/10.1186/s12245-020-00299
Sheraton, M., Doah, N., Dutt, T., Surani ,S., Hall-Flavin, D.\& Kashyap, R., (2020): Psychological effects of the COVID 19 pandemic on healthcare workers globally: A systematic review,Psychiatry Research, Vol.292

World Health Organization. (2021). Coronavirus Disease 2019 (COVID-19):

Situation Report

Zhang, C., Yang, L., Liu, S., Ma, S., Wang, Y., Cai, Z., Li, R., Kang, L., Su, M., Zhang, J., Liu, Z., \& Zhang, B. (2020). Survey of insomnia and related social psychological factors among medical staff involved in the 2019 novel coronavirus disease outbreak, Front Psychiatry, Vol. 11, No (306),doi: 10.3389/fpsyt.2020.00306 


\section{تأثير كوفيد 1 اعلى الحالة النفسية بين الممرضات العاملات في مستثفى العزل اسماء صلاح ابر اهيم ـ اميمة ابو بكر عثمان ـ فاتن محمد احمد}

كوفيد 9 (هو مرض معدي جديد يصيب ويقتل عددا كبير ا من الناس كل يوم حول العالم. يتعرض العاملون في

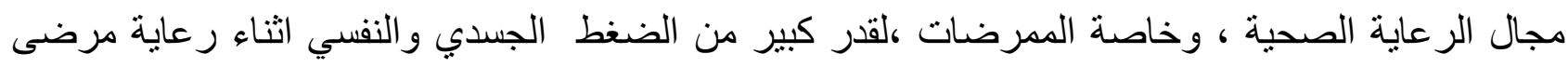

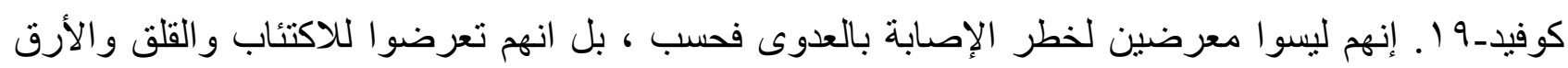

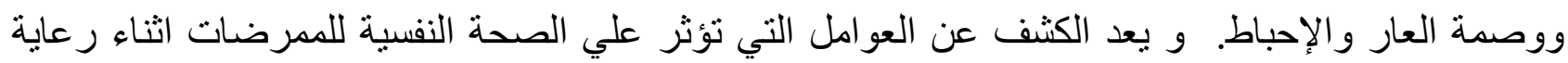
هؤلاء المرضي يمكن ان تساعد في تقليل ضغطهم النفسي. وضمان الدعم المناسب للصحة النفسيه و العقلية

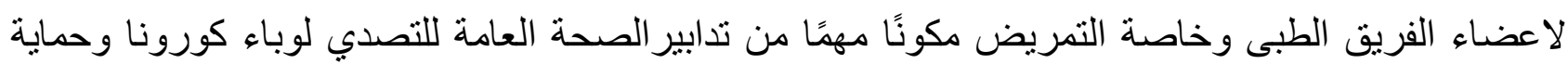

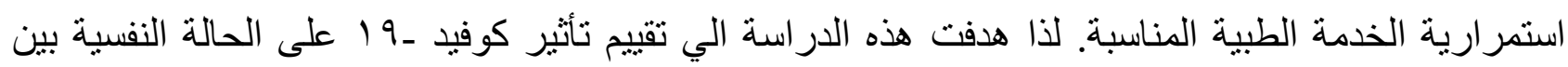

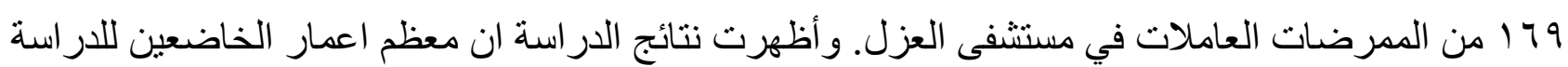

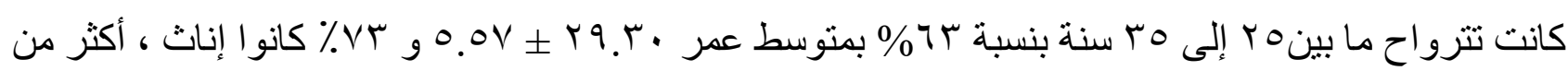

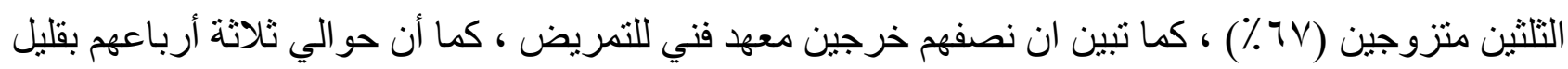

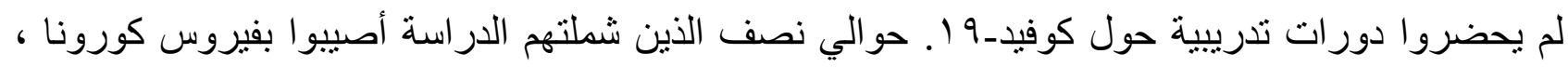

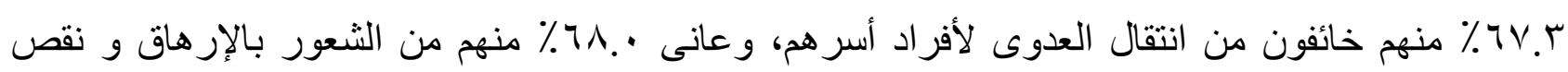
الطاقة. كما اوصت الدر اسة بضرورة الانتباه إلى الحالة الصحية النفسية للممرضات أثناء قيامهن بمسؤولياتهن. 